University of Nebraska - Lincoln

DigitalCommons@University of Nebraska - Lincoln

\title{
Use of mammal manure by nesting burrowing owls: a test of four functional hypotheses
}

\author{
Matthew D. Smith \\ University of Arizona, mdsmith@zoo.ufl.edu \\ Courtney J. Conway \\ University of Arizona, cconway@usgs.gov
}

Follow this and additional works at: https://digitalcommons.unl.edu/usgsstaffpub

Part of the Geology Commons, Oceanography and Atmospheric Sciences and Meteorology Commons, Other Earth Sciences Commons, and the Other Environmental Sciences Commons

Smith, Matthew D. and Conway, Courtney J., "Use of mammal manure by nesting burrowing owls: a test of four functional hypotheses" (2006). USGS Staff -- Published Research. 571.

https://digitalcommons.unl.edu/usgsstaffpub/571

This Article is brought to you for free and open access by the US Geological Survey at DigitalCommons@University of Nebraska - Lincoln. It has been accepted for inclusion in USGS Staff -- Published Research by an authorized administrator of DigitalCommons@University of Nebraska - Lincoln. 


\title{
Use of mammal manure by nesting burrowing owls: a test of four functional hypotheses
}

\author{
MATTHEW D. SMITH \& COURTNEY J. CONWAY \\ USGS Arizona Cooperative Fish and Wildlife Research Unit, School of Natural Resources, \\ The University of Arizona, Tucson \\ (Received 30 August 2005; initial acceptance 30 November 2005; \\ final acceptance 24 May 2006; published online 2 November 2006; MS. number: A10234)
}

\begin{abstract}
Animals have evolved an impressive array of behavioural traits to avoid depredation. Olfactory camouflage of conspicuous odours is a strategy to avoid depredation that has been implicated only in a few species of birds. Burrowing owls, Athene cunicularia, routinely collect dried manure from mammals and scatter it in their nest chamber, in the tunnel leading to their nest and at the entrance to their nesting burrow. This unusual behaviour was thought to reduce nest depredation by concealing the scent of adults and juveniles, but a recent study suggests that manure functions to attract arthropod prey. However, burrowing owls routinely scatter other materials in the same way that they scatter manure, and this fact seems to be at odds with both of these hypotheses. Thus, we examined the function of this behaviour by testing four alternative hypotheses. We found no support for the widely cited olfactory-camouflage hypothesis (manure did not lower the probability of depredation), or for the mate-attraction hypothesis (males collected manure after, not before, pair formation). Predictions of the burrow-occupied hypothesis (manure indicates occupancy to conspecifics and thereby reduces agonistic interactions) were supported, but results were not statistically significant. Our results also supported several predictions of the prey-attraction hypothesis. Pitfall traps at sampling sites with manure collected more arthropod biomass (of taxa common in the diet of burrowing owls) than pitfall traps at sampling sites without manure. Scattering behaviour of burrowing owls appears to function to attract arthropod prey, but may also signal occupancy of a burrow to conspecifics.
\end{abstract}

(c) 2006 The Association for the Study of Animal Behaviour. Published by Elsevier Ltd. All rights reserved.

Keywords: Athene cunicularia; burrowing owl; conspecific signalling; foraging tactics; manure scattering; olfactory camouflage; predator avoidance; prey attraction

Predation is thought to be one of the major ecological processes influencing population dynamics, community structure and life history evolution (Endler 1986; Kerfoot \& Sih 1987; Martin 2002; Remes \& Martin 2002). Indeed, animals have evolved an impressive array of traits to reduce predation risk, and the behaviours used to avoid depredation are a dominant feature of the behavioural repertoire of most animals (Alcock 1993). The most common behaviours for preventing detection by predators involve cryptic behaviour (resting without moving or adaptive nest site selection), fleeing, or removing cues that would otherwise reveal one's presence (Taylor 1984; Endler 1986; Ydenberg \& Dill 1986; Alcock

Correspondence and present address: M. Denman Smith, University of Florida, Department of Zoology, 223 Bartram Hall, PO Box 118525, Gainesville, FL 32611-8525, U.S.A. (email: mdsmith@zoo.ufl.edu).
1993; Durant 2000). In contrast, olfactory camouflage is a strategy that is less common and has been ignored in most reviews of predator avoidance tactics. Examples of visual camouflage are common, but examples of animals that use objects from the environment to mask their smell from predators are rare. One of the few examples of possible olfactory camouflage involves burrowing owls, Athene cunicularia, which collect mammal manure from the surrounding environment. Burrowing owls actively shred large clumps of manure to build their underground nest cup, to line the tunnel leading to the nest chamber, and to scatter around the entrance of their nest burrow (Bendire 1892; Scott 1940; Martin 1973). Collecting and scattering manure was long believed to be a behavioural adaptation to conceal scent from predators (Martin 1973; Green 1983; Green \& Anthony 1989; Haug et al. 1993; Desmond et al. 1997; Dechant et al. 2003; Holmes et al. 2003). However, recent studies 
suggest that manure functions as bait to attract prey rather than to avoid nest depredation (Levey et al. 2004; Smith 2004).

Both of these potential functions are extremely interesting because one represents a novel behaviour to avoid depredation and the other represents a novel foraging tactic. However, one aspect of this common behaviour in burrowing owls potentially contradicts both of these functional hypotheses. Some individuals scatter a variety of materials other than manure (e.g. grass, paper, cotton, dried moss; Thomsen 1971) in the same way that other individuals use manure. If burrowing owls use manure to repel predators or to attract prey, why would some use paper or grass in the same way when these materials do not clearly share the same predator-repelling or food-attracting properties as manure? Alternative hypotheses that account for the use of other materials have not been tested. For example, males may scatter manure and other materials at their nest site as an indication of individual quality. Alternatively, males may scatter material around their nest as a signal to conspecifics that their burrow is occupied. In this study, we tested multiple predictions of these four alternative hypotheses in southeastern Washington, U.S.A., to explain why burrowing owls scatter mammal manure and other materials at their nest site. Below is an explanation of the mechanism underlying each of these four hypotheses.

(1) Mate-attraction hypothesis. Structures (e.g. nests or mating sites) built by males of various taxa often contain features that reflect individual quality, and are used by females to choose among prospective mates (Borgia 1985; Barber et al. 2001). Evidence from videotaped nests suggests that scattering behaviour in burrowing owls is performed only by males (R. Poulin \& D. Todd, personal communication). Hence, in the same way that objects at bowers influence mate-choice in bowerbirds, female burrowing owls may use manure (and other materials) to assess male quality.

(2) Burrow-occupied hypothesis. Some bird species appear to use materials (green twigs) to inform conspecifics that a nest (Selas 1988) or territory (Bergo 1987) is occupied. Suitable nest burrows are in short supply for some populations of western burrowing owls, A. cunicularia hypugaea (Desmond \& Savidge 1996). Hence, suitable burrows may attract unpaired males searching for nesting opportunities. Burrowing owls will defend their burrows vigorously against nonresident males (Thomsen 1971; Martin 1973), thus resident males may scatter manure and other materials as a visual signal of occupancy to reduce costly agonistic interactions. Given that resident males of many species usually win territorial disputes (Davies 1978), nonresident males might not enter burrows that are littered with manure (or other materials) to avoid conflicts. For resident males, the benefit of reduced conflicts (even though they would typically win disputes) might surpass any energetic and survival costs associated with scattering behaviour.

(3) Olfactory-camouflage hypothesis. Antipredation behaviours that rely on olfactory camouflage are rare, but have been suggested in white-breasted nuthatches, Sitta carolinensis (Kilham 1968), parrots (Psittacidae) and trogons
(Trogonidae; Brightsmith 2000), and common waxbills, Estrilda astrild (Schuetz 2004). In western North America, badgers, Taxidea taxus, coyotes, Canis latrans, and striped skunks, Mephitis mephitis, are common nest predators of burrowing owls (Haug et al. 1993), and these predators rely on olfactory cues to locate prey (Knopf \& Balph 1969). Hence, the presence of mammal manure at burrowing owl nests may lower the probability of nest depredation by concealing odours associated with an active nest (Martin 1973; Green \& Anthony 1989).

(4) Prey-attraction hypothesis. Some organisms use strategies to attract, rather than stalk, prey (Davis \& Kushlan 1994; Moran 1996; Atkinson 1997). Arthropods are often attracted to manure (Rodriguez et al. 2003), and some insectivorous birds travel to manure deposits to forage for arthropods (Beintema et al. 1991; Ruggiero \& Eves 1998). Arthropods constitute approximately 90\% of total diet (by number) and 15\% of prey biomass for western burrowing owls (Marti 1974; Gleason \& Craig 1979; Green et al. 1993). Thus, scattered manure may attract arthropods to burrowing owl nests and increase food availability (Levey et al. 2004; Smith 2004).

In this study, we used the hypothetico-deductive method to test several predictions of each of these four functional hypotheses. We used a combination of observational and experimental approaches to help determine the function of manure-scattering behaviour in burrowing owls.

\section{METHODS}

We conducted research from February to September 2000-2002, in southeastern Washington, U.S.A. The $\sim 520-\mathrm{km}^{2}$ study site in Franklin and Benton counties is $117 \mathrm{~m}$ above sea level and encompasses the towns of Richland, Kennewick and Pasco. Average annual rainfall is $17 \mathrm{~cm}$. Land use in these counties includes native shrubsteppe, urban, suburban, industrial, agricultural, and horse and cattle grazing. Burrowing owl nests used for this study were located in all types of land use, except dense urban areas. Nests were predominantly located in fields with little human presence, but where the native shrub-steppe had been moderately disturbed (Smith 2004). Burrowing owls used for this study were part of a banded population being observed for a large-scale demography study (Conway et al. 2006).

The mate-attraction hypothesis can potentially account for the use of materials other than manure. If females use either manure or other materials to assess the quality of potential mates, then males would begin scattering behaviour before pair formation (prediction 1, Table 1). To test this prediction, we estimated the number of days before or after pair formation that males began scattering any material. From 20 February to 30 September 2002 , we monitored 46 nesting burrows (each used by a pair of burrowing owls). We visited each burrow every 2-4 days and recorded the presence of manure and other materials at the burrow entrance, the number of adults and juveniles visible, and any signs of depredation. We then estimated the date of pair formation (date of female 
Table 1. Predictions of four alternative hypotheses to explain the function of the manure-scattering behaviour of burrowing owls. Tests of these predictions were conducted in southeastern Washington from February to August 2001-2002

\begin{tabular}{|llll|}
\hline & & \multicolumn{2}{c|}{ Hypothesis } \\
\cline { 2 - 3 } Predictions & Mate attraction & Burrow occupied & Olfactory camouflage Prey attraction \\
\hline (1) Stage of nesting cycle when manure is collected & Before pair formation & Soon after arrival Just before incubation & All stages* \\
(2) Presence of manure at traditional nests before & No & No & No \\
owls return from migration discourages nesting & & No & No \\
(3) Increased perception of competition increases & Yes/no & Yes & No \\
manure scattering & No & No & No \\
(4) Higher fecundity at nests with manure & No & Yes \\
(5) Lower depredation at natural nests with manure & No & Yes & No \\
(6) Lower depredation at artificial nests with manure & No & No & No \\
(7) More arthropod biomass at nests with manure & No & & Yos \\
\hline
\end{tabular}

*Probably more common after pair formation, and most common during the nesting stage when food is most limiting.

arrival; females rarely switched mates after being observed at a burrow), and the date that scattering behaviour was first observed at each occupied burrow. To test whether this behaviour began before pair formation, we used a one-sample $t$ test.

The burrow-occupied hypothesis predicts that if scattered manure signals occupancy, then its presence would deter males from occupying a burrow (prediction 2, Table 1). To test this prediction, we randomly selected a sample of 38 burrows that were used as nesting burrows in both 2000 and 2001. In February 2002, before males returned from migration (11 March \pm 2 days), we scattered 4 litres of shredded horse manure at the burrow entrance and in the first $0.5 \mathrm{~m}$ of the burrow tunnel at 19 of the 38 burrows. The other 19 burrows served as controls and at these we removed all material from previous years. We visited all 38 burrows twice weekly from 28 February to 31 August 2002 to determine which were used as nests. We used a contingency table analysis to compare the proportion of burrows that became nests between manure-supplemented and control burrows.

The burrow-occupied hypothesis can also account for the use of materials other than manure. This hypothesis predicts that resident males with more intense competition for their burrow would scatter more manure or other materials (either as an amplification of the 'occupied' signal, or to ensure that the signal is readily visible) compared to males with little competition (prediction 3 , Table 1). In April 2002, we artificially increased the perception of competition for 20 resident males by presenting them with a taxidermic mount and the primary call of a male burrowing owl. As a control, we presented 12 other males with a taxidermic mount and the primary call of a European starling, Sturnus vulgaris. For all presentations, we placed the mount and broadcast speaker $10 \mathrm{~m}$ away from the nesting burrow (at a random azimuth). We conducted three 10-min presentations (one during 06001100 hours, one during 1300-1700 hours, and one during 2000-2400 hours) at each burrow within a 4-day period from 12 to 22 April (96 total presentations). The call stimulus for both experimental (burrowing owl mount) and control (starling mount) trials consisted of $30 \mathrm{~s}$ of calls followed by $30 \mathrm{~s}$ of silence, repeated for either $10 \mathrm{~min}$ or until an owl attacked the mount. We examined the efficacy of our burrowing owl mount in creating the perception of competition by recording the response of resident males during each presentation. Before the first presentation we removed all materials at the burrow entrance and within the first $0.5 \mathrm{~m}$ of the tunnel at each nesting burrow. At each of the 32 nesting burrows, we collected all scattered material 7 days after the third presentation. We used a digital scale to measure mass (dry weight) to the nearest gram, and water displacement to measure volume to the nearest millilitre of all materials collected by owls after the presentations. To test whether mass and volume of material collected (after the presentations) was higher at nests presented with the owl mount, we logtransformed the mass and volume of material (to correct unequal variance) and then used a one-tailed $t$ test. We used a one-tailed test because we were testing an a priori directional prediction. We used logistic regression analysis to examine whether mount type (burrowing owl or starling) affected the probability that resident males would attack the mount. We also included nesting stage, time of day and the number $(1-3)$ in our series of presentations as explanatory variables in the regression model because we thought that each of these variables might affect the response of resident males.

We tested a third prediction of the burrow-occupied hypothesis: that males should begin scattering behaviour soon after arrival from migration (prediction 4, Table 1). Hence, we recorded the date of male arrival and the date that any material was first observed at each of the 46 monitored nests (see Methods of Mate-attraction hypothesis).

The olfactory-camouflage hypothesis predicts that if manure conceals nest odours, then nests with manure would have a lower probability of depredation than nests without manure (prediction 5, Table 1 ). We randomly selected 24 active nests at which to add or remove manure. We paired manure-supplemented and manure-removed nests to control for spatial variation in land use and predator density. We randomly assigned nests in each pair to the two treatments. From 15 April to 25 July 2001 we visited each nest every 2-4 days to add or remove manure. The 12 manure-supplemented nests received 2 litres of shredded horse manure on each visit, and at the 12 
manure-removed nests we removed all manure (and all other materials) from the burrow entrance and the first $0.5 \mathrm{~m}$ of the tunnel on each visit. On each visit we also recorded the number of adults and juveniles, and any signs of nest depredation. We used a contingency table analysis to compare the proportion of active nests depredated between manure-supplemented and manure-removed treatments.

We also used artificial nests to test this hypothesis (prediction 6, Table 1). In May 2001, we placed three chicken eggs (which we assumed were as attractive as a clutch of owl eggs to a likely burrowing owl nest predator) approximately $1 \mathrm{~m}$ inside each of 48 unoccupied burrows. We separated burrows into 12 groups of four based on proximity. Each burrow was then supplemented with one of four randomly assigned treatments: (1) horse manure (4 litres) and owl sign (feathers and pellets), (2) coyote scat (100 g) and owl sign, (3) no manure or scat, but owl sign, and (4) no manure, scat, or owl sign. Hence, each of the 12 groups had one burrow in each of the four treatments. We supplemented burrowing owl sign (15 pellets and 10 feathers) to aid in simulating an active nest. We included coyote scat because it was found frequently at owl nests, might either intrigue or scare away large predators, and should scare away small predators better than horse manure (Schuetz 2004). We revisited each of the 48 artificial clutches after 3 weeks and recorded any signs of depredation using an infrared fibrescope (Peeper Video Probe, Sandpiper Technologies, Manteca, California, U.S.A.). We used a contingency table analysis to compare the proportion of artificial nests depredated among the four treatments.

The prey-attraction hypothesis predicts that scattered manure would attract species of arthropods typically eaten by burrowing owls (prediction 7, Table 1). We tested this prediction by comparing abundance of arthropods sampled between sites with and without manure. We sampled potential prey in areas that appeared to be suitable for burrowing owls and were within $1.5 \mathrm{~km}$ of active nests (ensuring that we had sampled in burrowing owl habitat), but were not closer than $200 \mathrm{~m}$ to an occupied nest (ensuring that arthropods were available for sampling). In June of 2000 and 2001, we used pitfall traps (and the following experimental design; Fig. 1) to sample arthropods. Each pitfall trap was a 473-ml (16-oz) plastic cup with a clear funnel stapled inside the cup and $60 \mathrm{ml}$ of soapy water to prevent the escape of captured arthropods. We set a total of 450 traps at 75 sampling areas $(N=46$ in 2001 and 29 in 2002). Each of the 75 sampling areas contained two treatment sites: experimental (with 2 litres of manure) and control (without manure). At each treatment site we placed three pitfall traps in a triangular pattern (approximately $15 \mathrm{~cm}$ apart).

An additional component of our design considered the interaction between arthropods and the microclimate of a burrow (Coulumbe 1971; Anduaga \& Halffter 1991). We did not know a priori if the presence of a burrow would affect arthropod abundance, and suitable, unoccupied burrows were uncommon in our study area. Thus, some $(N=30)$ sampling areas were associated with unoccupied burrows, and others $(N=45)$ were not. This allowed us

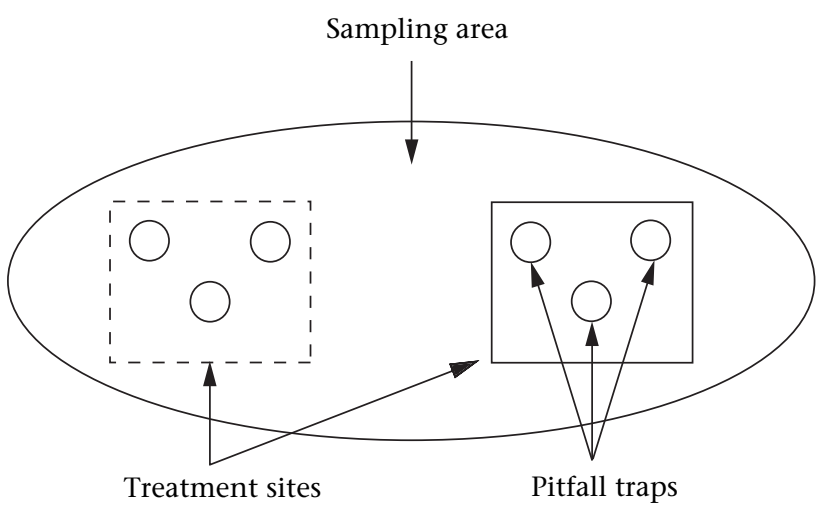

Figure 1. Diagram of general experimental design used to test the prey-attraction hypothesis in southeastern Washington in June 2001 and 2002. Each sampling area (oval) contained two treatment sites: an experimental site with manure (solid square), and a control site without manure (dashed square). Each experimental and control site contained three pitfall traps (circles). We set a total of 450 traps: six traps per site (three experimental and three control) $\times 75$ sampling areas $=450$ total traps.

to compare arthropod abundance between burrow and nonburrow areas (and to increase our sample size if there was no difference). For sampling areas at burrows, we located two unoccupied burrows and randomly assigned one as experimental (with manure) and the other as control (no manure). The two burrows in each pair ranged from 10 to $300 \mathrm{~m}$ apart (i.e. close enough to be similar in vegetation, predator abundance, land use and human disturbance). For sampling areas not associated with a burrow, we first walked $50 \mathrm{~m}$ into a suitable area (using a randomly chosen azimuth). At $50 \mathrm{~m}$, we threw a marker flag in a random direction and placed the first treatment site where the flag landed. We randomly assigned this site as either experimental or control, and then placed the paired site $10 \mathrm{~m}$ away (in a randomly chosen direction). In 2001, we collected arthropods from pitfall traps after 14 days. In 2002 , we collected arthropods from pitfall traps after only 6 days because of concern that other arthropods had consumed some samples in the 2001 traps during the longer sampling period. The difference in sampling duration across years did not bias our results because we used a paired analytical approach and we included year as a covariate in our analysis.

To quantify the effects of manure on arthropod abundance we estimated the biomass (mg of dry weight) of captured arthropods. We included only those taxa previously reported in the diet of burrowing owls in western North America (see Smith 2004 and references therein). For arthropods that were whole, we measured total body length, then used an appropriate allometric equation (Rogers et al. 1976, 1977) to obtain an estimate of biomass. We also used the whole arthropods to develop additional allometric equations to predict total body length from various body parts (e.g. thorax, femur). We used these allometric equations (Smith 2004) to estimate total body length (and biomass) for those arthropods in our pitfall traps that were not whole. We then calculated average arthropod biomass per trap. We used average biomass per 
trap (as opposed to total biomass in all three traps) because occasionally a trap was unusable because it became filled with sand or manure. To compare arthropod biomass between manure and nonmanure sites we used a repeated measures ANOVA. We used arthropod biomass at manure and nonmanure sites as the within-subjects factor (i.e. the repeated measure) and presence of a burrow and the year of collection as between-subjects factors to control for these variables in our analysis.

Another prediction of the prey-attraction hypothesis is that manure should increase fecundity (Table 1) because supplementing food at nests increases fecundity in burrowing owls (Wellicome 2000). For each of the 12 manure-supplemented and 12 manure-removed nests (see Methods of olfactory-camouflage hypothesis) we recorded the maximum number of 21-day-old juveniles observed above ground during our weekly nest visits. Because we were testing an a priori directional prediction, we used a one-tailed $t$ test to determine whether the number of juveniles was higher at manure-supplemented nests.

Our sample sizes were relatively small for some of our tests, so we report $95 \%$ confidence intervals for comparisons that yielded nonsignificant results. Confidence intervals are more appropriate than post hoc power analyses on observed differences in this regard (Hoenig \& Heisey 2001; Colegrave \& Ruxton 2003; Johnson 2005) because they allow readers to see the effect sizes that are supported by the data and those that are not.

\section{RESULTS}

\section{Mate-attraction Hypothesis}

Of the 46 males that we monitored that obtained mates, 21 scattered manure at their nest burrow (all 21 also scattered other materials). Excluding two nests for which material type was not recorded on the first observation, the date that manure first appeared (13 April) and the date that other materials first appeared (15 April) did not differ (two-tailed, one-sample $t$ test: $t_{18}=0.4, P=0.694 ; 95 \%$ CI: -7.6 days, 11.2 days). Twenty-five males scattered only other materials. Contrary to the prediction for this hypothesis, scattering behaviour began after pair formation $(\bar{X}=9.4 \pm 2$ days $)$ at $87 \%$ of the 46 nest burrows $\left(t_{45}=5.8, P<0.001\right.$; Table 2).

\section{Burrow-occupied Hypothesis}

The proportion of burrows that became nests was 58\% for burrows where we added manure and 78\% for burrows where we removed manure. The pattern was in the direction predicted by the burrow-occupied hypothesis and a difference of $21 \%(95 \% \mathrm{CI}$ : $-8 \%, 50 \%)$ suggests a biologically meaningful effect even though the difference was not statistically significant (Fisher's exact test: $P=0.148)$. Resident males were more likely to attack a burrowing owl mount than a European starling mount (Wald's chi-square test: $\chi_{1}^{2}=7.9, P=0.005$ ). After three presentations of a burrowing owl mount, resident males scattered $135 \pm 33 \mathrm{~g}\left(232 \pm 49 \mathrm{~cm}^{3}\right)$ of material. After three presentations of a starling mount, resident males scattered $99 \pm 23 \mathrm{~g}\left(196 \pm 44 \mathrm{~cm}^{3}\right)$ of material. The patterns were again in the direction predicted by the burrow-occupied hypothesis with an average difference of $36 \mathrm{~g}$ of material (95\% CI: $-56 \mathrm{~g}, 129 \mathrm{~g}$ ), but the differences were not statistically significant (biomass: $t_{32}=1.3$, $P=0.105$; volume: $\left.t_{32}=0.5, P=0.301\right)$ owing to large variation among owls. Contrary to our third prediction that males should initiate scattering behaviour soon after arrival from migration, males did not begin until $28 \pm 3$ days after arrival following spring migration.

\section{Olfactory-camouflage Hypothesis}

The two predictions of this hypothesis were not supported. Of the naturally occupied nests, only one manuresupplemented nest was depredated (8\%; 95\% CI: 0\%, $24 \%$ ) and one manure-removed nest (8\%; 95\% CI: 0\%, $24 \%$ ) failed for unknown reasons (possibly depredation). Hence, probability of depredation between the two treatments did not differ (Fisher's exact test: $P=0.783$ ). Similarly, only four of the 48 (8\%) experimental (artificial) nests were depredated, and we found no difference in probability of nest depredation among the four treatments (Pearson chi-square test: $\chi_{3,44}^{2}=2.2, P=0.535$ ).

\section{Prey-attraction Hypothesis}

In our pitfall traps, we collected 4019 arthropods from 11 orders and 19 families that had previously been reported in the diet of burrowing owls (Table 3). Average arthropod biomass was higher at manure sites

Table 2. Mean \pm SE dates in 2002 when burrowing owls arrived at nest burrows following spring migration, mean \pm SE dates when burrowing owls initiated manure-scattering behaviour (MSB) and the mean \pm SE number of days after arrival that manure-scattering behaviour (MSB) began for 46 nests in southeastern Washington

\begin{tabular}{|c|c|c|c|c|c|c|c|}
\hline & \multirow[b]{2}{*}{$N$} & \multicolumn{2}{|c|}{ Arrival date } & \multicolumn{2}{|c|}{ Date that MSB began } & \multicolumn{2}{|c|}{ Days after arrival that MSB began } \\
\hline & & $\bar{X} \pm \mathrm{SE}$ & $95 \% \mathrm{Cl}$ & $\bar{X} \pm \mathrm{SE}$ & $95 \% \mathrm{Cl}$ & $\bar{X} \pm \mathrm{SE}$ & $95 \% \mathrm{Cl}$ \\
\hline Single males & 8 & $21 \mathrm{Mar} \pm 9$ & $27 \mathrm{Feb}-11 \mathrm{Apr}$ & $19 \mathrm{Apr} \pm 7$ & $2 \mathrm{Apr}-5$ May & $29 \pm 8$ & $11-47$ \\
\hline Paired males & 46 & $11 \operatorname{Mar} \pm 2$ & $9 \mathrm{Mar}-15 \mathrm{Mar}$ & $9 \mathrm{Apr} \pm 3$ & $4 \mathrm{Apr}-13 \mathrm{Apr}$ & $28 \pm 3$ & $23-33$ \\
\hline Females* & 46 & $30 \mathrm{Mar} \pm 2$ & $26 \mathrm{Mar}-3 \mathrm{Apr}$ & $9 \mathrm{Apr} \pm 3$ & $4 \mathrm{Apr}-13 \mathrm{Apr}$ & $9 \pm 2$ & $6-13$ \\
\hline
\end{tabular}

*Arrival date of females equals date of pair formation. 
Table 3. Number of individuals and total biomass of all taxonomic orders and families of arthropods collected in pitfall traps in southeastern Washington in 2001 and 2002

\begin{tabular}{|c|c|c|c|c|}
\hline Order & $\begin{array}{c}\text { Number } \\
\text { of } \\
\text { individuals }\end{array}$ & $\begin{array}{l}\text { Biomass } \\
(\mathrm{mg})\end{array}$ & $\begin{array}{l}\text { Percentage } \\
\text { of } \\
\text { individuals }\end{array}$ & $\begin{array}{l}\text { Percentage } \\
\text { of biomass }\end{array}$ \\
\hline $\begin{array}{l}\text { Araneae and } \\
\text { Solpugida }\end{array}$ & 242 & 6979 & 6 & 9 \\
\hline Coleoptera & 868 & 35648 & 22 & 47 \\
\hline Diptera & 19 & 606 & 1 & 1 \\
\hline Hemiptera & 14 & 48 & $<1$ & $<1$ \\
\hline Hymenoptera & 2288 & 4643 & 57 & 6 \\
\hline Isopoda & 183 & 821 & 5 & 1 \\
\hline Lepidoptera & 11 & 694 & $<1$ & 1 \\
\hline Odonata & 1 & 570 & $<1$ & 1 \\
\hline Orthoptera & 391 & 25396 & 10 & 33 \\
\hline Scorpiones & 2 & 540 & $<1$ & 1 \\
\hline
\end{tabular}

$(215 \pm 21 \mathrm{mg}) \quad$ compared to nonmanure sites $(127 \pm 13 \mathrm{mg}$ ) (biomass main effect in Table 4; Fig. 2). Year and the interaction between year and burrow presence explained additional variation in insect biomass (Table 4) and these effects were probably due to our change from the 14-day to 6-day sampling interval. These between-subject effects did not interact with our main effect (difference in biomass between manure and nonmanure sites) and were appropriately controlled for in our analysis (Table 4). Treatment sites with manure contained $88 \pm 21 \mathrm{mg}$ more average biomass per trap than sites without manure.

We found no difference (one-tailed $t$ test: $t_{11}=-1.5$, $P=0.912$ ) in the mean number of young surviving to 21 days of age between the 12 manure-removed $(4.1 \pm 0.7)$ and the 12 manure-supplemented nests $(3.2 \pm 0.7)$. The average difference between the two treatment groups was 0.9 young surviving (95\% CI: -2.31 young, 0.48 young), but the pattern was in the opposite direction of that predicted by the prey-attraction hypothesis.

Table 4. Repeated measures ANOVA of arthropod biomass collected in pitfall traps at manure sites compared to nonmanure sites in southeastern Washington in 2001 and 2002

\begin{tabular}{|c|c|c|c|c|}
\hline & \multicolumn{4}{|c|}{ Average arthropod biomass } \\
\hline & df & MS & $F$ & $P$ \\
\hline \multicolumn{5}{|l|}{ Within-subjects effects } \\
\hline Biomass & 1 & 238312 & 14.6 & $<0.001$ \\
\hline $\begin{array}{l}\text { Biomass } \times \text { burrow } \\
\text { presence }\end{array}$ & 1 & 18 & 0.001 & 0.974 \\
\hline Biomass $\times$ year & 1 & 1 & 0.001 & 0.994 \\
\hline $\begin{array}{l}\text { Biomass } \times \text { year } \times \text { burrow } \\
\text { presence }\end{array}$ & 1 & 12125 & 0.7 & 0.394 \\
\hline Error (biomass) & 71 & 16487 & & \\
\hline \multicolumn{5}{|l|}{ Between-subjects effects } \\
\hline Intercept & 1 & 3247764 & 112.3 & $<0.001$ \\
\hline Burrow presence & 1 & 2789 & 0.1 & 0.757 \\
\hline Year & 1 & 134619 & 4.7 & 0.034 \\
\hline Burrow presence $\times$ year & 1 & 231917 & 8.0 & 0.006 \\
\hline Error & 71 & 28926 & & \\
\hline
\end{tabular}

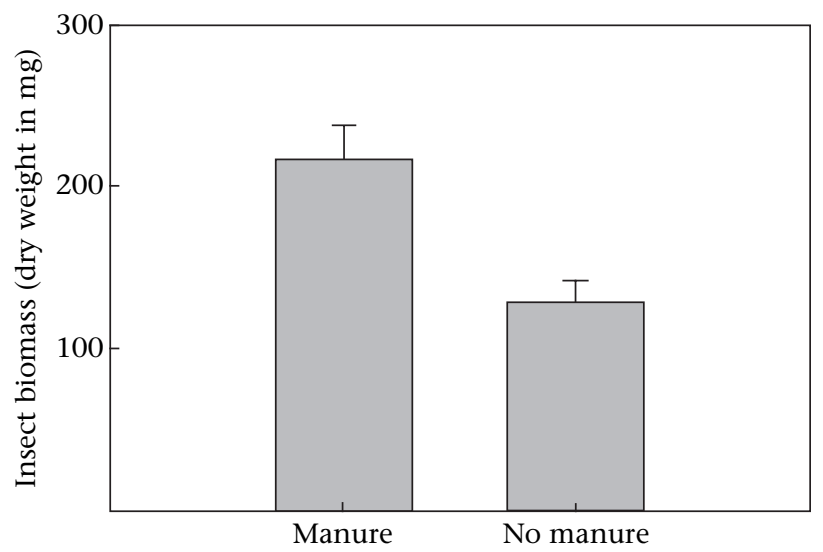

Figure 2. Mean \pm SE biomass ( $\mathrm{mg}$ ) of arthropods caught in pitfall traps at paired sites with and without supplemented manure in southeastern Washington in 2001 and 2002.

\section{DISCUSSION}

Before testing alternative hypotheses, we first considered the most parsimonious explanation: that scattered manure (or other material) is a by-product of nest building. Birds generally use materials from the local environment to build nests (Hansell 2000), and manure tends to be common in areas where burrowing owls typically nest. Thus, burrowing owls simply may drop excess nest-building material, or males may deliver material for females to use in nest building. Yet, the seasonal timing of this behaviour does not support either explanation: males continued bringing manure and other materials to the nest burrow even after the clutch was complete. Hence, scattering behaviour appears to have some function beyond nest building. We found no evidence that the use of manure or other materials functions to attract mates: scattering behaviour began after pair formation for nearly all nests monitored. Our results did not support the widely cited hypothesis that manure conceals nest scents and reduces depredation. Instead, our results support the hypothesis that manure attracts arthropod prey to burrowing owl nests. Our results also provide tentative support for a novel hypothesis: that manure and other materials signal burrow occupancy to conspecifics. Prey attraction and occupancy signalling are not mutually exclusive functions; perhaps the habit of scattering materials initially evolved to signal occupancy, and the use of manure in this regard provided an added benefit (attracting prey to the nest).

Although the timing of scattering behaviour accords with the olfactory-camouflage hypothesis (after pair formation to conceal scent of offspring), we found no support for the other two predictions. Probability of depredation did not differ between manure-supplemented and manure-removed nests. Although our sample sizes were relatively small, two other recent experimental studies (Brady 2004; Levey et al. 2004) also did not find support for this hypothesis.

We did find tentative support for the burrow-occupied hypothesis. Burrows where we added manure before males returned from migration were 36\% less likely to become nests compared to burrows with no manure (although the 
difference was not statistically significant). The lack of significance may be due to our small sample size and some unavoidable logistical constraints associated with our experiment. We supplemented manure 2 months before the average date at which scattering behaviour typically begins (because we needed manure to be present upon male arrival). Males may differentiate between freshly scattered manure and manure that has been present for several months. Or, they may have been initially deterred by the manure, but simply waited a few days before realizing that no other male was present (our sampling frequency would not have detected this response). The burrowing owl taxidermic mount was effective at eliciting a stronger territorial response from resident males compared to the starling mount. Although the amount of material collected was not statistically different between treatments, the pattern was in the predicted direction (experimental males collected $27 \%$ more biomass and $16 \%$ more volume of material than did control males). However, instead of collecting manure immediately after returning from migration (as predicted by the burrowoccupied hypothesis), males waited an average of 28 days before bringing material to their burrow. Given that all males do not secure mates, perhaps waiting until females begin arriving is a more efficient strategy. Hence, our results suggest that this hypothesis deserves further testing with larger sample sizes.

Our results support an important assumption of the preyattraction hypothesis. Pitfall traps at experimental sites with manure had 69\% more average arthropod biomass per trap than did pitfall traps at control sites without manure. Our observed effect of manure may be an underestimate because sampling probably did not capture all prey at a site (i.e. each trap covered only a small area). For example, when we increased sampling area three-fold by considering a subset of 48 sampling areas where all three traps per treatment were useable, there was $76 \%$ more biomass at the manure treatment (Smith 2004). While our results do not show that burrowing owls actually consumed arthropods attracted by the manure, it seems reasonable to assume that they would. Indeed, the proportion of arthropods that we captured was similar to the proportion reported in studies of burrowing owl diet (e.g. Gleason \& Craig 1979). Moreover, Levey et al. (2004) found that eastern burrowing owls, Athene cunicularia floridana, ate arthropods attracted to manure. Attracting arthropods should be most beneficial during the stage of the nesting cycle when food is most limiting (i.e. during the nestling period), yet most burrowing owls started scattering manure well before hatching (i.e. during the laying period). However, such timing makes sense if manure functions to attract prey for incubating females because males must simultaneously provide all food for the incubating female and protect the clutch/brood from potential predators.

In contrast to an important prediction of the preyattraction hypothesis, we did not detect more juveniles at nests where we continually added manure. However, manure remaining in the lower tunnel of manure-removed nests may still have attracted arthropods. Or, perhaps the additional prey attracted by the manure increased condition (but not number) of offspring. An obvious question is: 'Why would burrowing owls collect manure to attract arthropods when they could just spend that time collecting arthropods?' We can think of several reasons why the former strategy might be more profitable. First, scattering manure to attract arthropods to the nesting burrow may provide juveniles with experience handling prey near the safety of the burrow. Second, scattering manure before and during egg laying may reduce the number (or length) of foraging bouts by adults once nestlings need to be fed. Hence, future studies should evaluate the effect of manure supplementation on fecundity, nestling growth rates, prey-handling ability of fledglings, and number and length of adult foraging bouts.

There are numerous other hypotheses that we did not test to explain the use of mammal manure. One in particular deserves mention. Manure may aid adult and juvenile burrowing owls in acquiring carotenoids (E. Korpimäki, personal communication). Carotenoids enhance immune function, and animals must obtain carotenoids from their diet (Møller et al. 2000). Thus, burrowing owls may collect and consume mammal manure to increase survival and reproductive success. Indeed, Egyptian vultures, Neophron percnopterus, consume ungulate manure as a source of carotenoids (Negro et al. 2002). The timing of scattering behaviour in burrowing owls coincides with what this hypothesis predicts: females may compensate for carotenoid loss to egg yolk early in the nesting cycle by eating mammal manure during later stages. This may be especially important for species with unusually large clutch sizes such as burrowing owls (up to 12 eggs; Haug et al. 1993). Additionally, owls may use manure to indirectly acquire carotenoids through the attraction of arthropod prey. Insectivorous birds have higher concentrations of plasma carotenoids $(\mu \mathrm{g} / \mathrm{ml})$ compared to birds that eat only mammals (Tella et al. 2004). Thus, scattering manure to attract arthropods may increase carotenoid consumption and therefore improve condition and survival of adults and juveniles. In fact, this hypothesis might help to explain why burrowing owls often switch from eating mammals to eating arthropods just prior to breeding (Haug et al. 1993).

One important aspect of scattering behaviour cannot easily be explained by the prey-attraction (or the carotenoid acquisition) hypothesis. While burrowing owls often used manure, they also scattered other materials near their nest (e.g. grass, moss, pieces of wood, shredded carpet, paper, plastic, cotton, dried vegetables, tin foil). The use of other materials has been reported elsewhere (Thomsen 1971), but previous authors (Green \& Anthony 1989; Levey et al. 2004) have focused solely on explaining the function of manure scattering. Males may use other materials for several reasons. First, they might scatter other materials that are similar in size, shape, or texture to manure because these materials trigger a 'collect and scatter' response (i.e. function as sign-stimuli). As a result, use of these materials may be 'maladaptive', similar to how some birds attempt to incubate golf balls or light bulbs (Conover 1985). Second, use of other materials might serve a similar function to manure. For example, they might attract arthropod prey by providing food or retaining moisture preferred by arthropods. Third, manure and 
other materials may serve some other function not considered here (e.g. insulation, flood absorption). Fourth, all materials may signal occupancy of a burrow, but males prefer manure when it is available for the added benefit of attracting prey. Additional research is needed to determine whether use of manure and use of other materials by burrowing owls serve the same or different functions. A fuller understanding of why burrowing owls use mammal manure may help to explain how burrowing owl populations have been affected by large-scale changes in mammal distribution, such as the removal of large ungulates from many portions of the Great Plains of North America (MacDonald 1984).

\section{Acknowledgments}

The U.S. Geological Survey, The University of Arizona Agricultural Experiment Station, The American Museum of Natural History's Frank Chapman Memorial Fund, and Sandpiper Technologies provided funding. C. Forristal, D. Hearne, M. Hearne, S. Millus, A. Sanfaçon, C. Sanders and P. Ramey assisted with fieldwork. A. Badyaev, B. Buskirk, V. Garcia, K. Hughes, P. Jablonski, D. Levey, W. Mannan, W. Matter, B. Pasch and P. Sherman provided insightful discussion and helpful comments. J. E. Wallace helped with arthropod identification, and C. Yde provided administrative assistance. We thank E. Korpimäki, D. A. Nelson and an anonymous referee for comments that greatly improved the quality of this manuscript.

\section{References}

Alcock, J. 1993. Animal Behavior: an Evolutionary Approach. 5th edn. Sunderland, Massachusetts: Sinauer.

Anduaga, S. \& Halffter, G. 1991. Beetles associated with rodent burrows. Folia Entomologica Mexicana, 81, 185-197.

Atkinson, E. C. 1997. Singing for your supper: acoustical luring of avian prey by northern shrikes. Condor, 99, 203-206.

Barber, I., Nairn, D. \& Huntingford, F. A. 2001. Nests as ornaments: revealing construction by male sticklebacks. Behavioral Ecology, 12, 390-396.

Beintema, A. J., Thissen, J. B., Tensen, D. \& Visser, G. H. 1991. Feeding ecology of Chadriiform chicks in agricultural grasslands. Ardea, 79, 31-43.

Bendire, C. E. 1892. Western burrowing owl. In: U.S. National Museum Bulletin No. 170, Life Histories of North American Birds. Part 2 (Ed. by A. C. Bent), pp. 384-396. Washington, D.C.: U.S. Government Printing Office.

Bergo, G. 1987. Territorial behavior of golden eagles in western Norway. British Birds, 80, 361-376.

Borgia, G. 1985. Bower quality, number of decorations and mating success of male satin bowerbirds: an experimental analysis. Animal Behaviour, 33, 266-271.

Brady, R. 2004. Effects of mammalian dung in burrowing owl nests: tests of alternative hypotheses. M.S. thesis, Boise State University, Boise, Idaho, U.S.A.

Brightsmith, D. J. 2000. Use of arboreal termitaria by nesting birds in the Peruvian Amazon. Condor, 102, 529-538.

Colegrave, N. \& Ruxton, G. D. 2003. Confidence intervals are a more useful complement to nonsignificant tests than are power calculations. Behavioral Ecology, 14, 446-447.
Conover, M. R. 1985. Foreign objects in bird nests. Auk, 102, 696700.

Conway, C. J., Garcia, V., Smith, M. D., Ellis, L. A. \& Whitney, J. 2006. Demography of burrowing owls within agricultural and urban landscapes in southeastern Washington. Journal of Field Ornithology, 77, 280-290.

Coulumbe, H. N. 1971. Behavior and population ecology of the burrowing owl in the Imperial Valley of California. Condor, 73, 162176.

Davies, N. B. 1978. Territorial defence in speckled wood butterfly: resident always wins. Animal Behaviour, 26, 138-147.

Davis, W. E., Jr \& Kushlan, J. A. 1994. Green heron (Butorides virescens). In: The Birds of North America. No. 129 (Ed. by A. Poole \& F. Gill). Philadelphia: The Birds of North America.

Dechant, J. A., Sondreal, M. L., Johnson, D. H., Igl, L. D., Goldale, C. M., Rabie, P. A. \& Euliss, B. R. 2003. Effects of Management Practices on Grassland Birds: Burrowing Owls. Jamestown, North Dakota: Northern Prairie Wildlife Research Center.

Desmond, M. J. \& Savidge, J. E. 1996. Factors influencing burrowing owl (Speotyto cunicularia) nest densities and numbers in western Nebraska. American Midland Naturalist, 136, 143-148.

Desmond, M. J., Savidge, J. E. \& Ekstein, R. 1997. Prairie partners. Nebraskaland, 75, 16-25.

Durant, S. M. 2000. Predator avoidance, breeding experience, and reproductive success in endangered cheetahs, Acinonyx jabatus. Animal Behaviour, 60, 121-130.

Endler, J. A. 1986. Defense against predation. In: Predator-Prey Relationships: Perspectives and Approaches from the Study of Lower Vertebrates (Ed. by M. E. Feder \& G. V. Lauder), pp. 109-134. Chicago: University of Chicago Press.

Gleason, R. L. \& Craig, T. H. 1979. Food habits of burrowing owls in southeastern Idaho. Great Basin Naturalist, 39, 274-276.

Green, G. A. 1983. Ecology of breeding burrowing owls in the Columbia Basin, Oregon. M.S. thesis, Oregon State University.

Green, G. A. \& Anthony, R. G. 1989. Nesting success and habitat relationships of burrowing owls in the Columbia Basin, Oregon. Condor, 91, 347-354.

Green, G. A., Fitzner, R. E., Anthony, R. G. \& Rogers, L. E. 1993. Comparative diets of burrowing owls in Oregon and Washington. Northwest Science, 67, 88-93.

Hansell, M. H. 2000. Bird Nests and Construction Behavior. Cambridge: Cambridge University Press.

Haug, E. A., Millsap, B. A. \& Martell, M. S. 1993. Burrowing owl (Speotyto cunicularia). In: The Birds of North America. No. 61 (Ed. by A. Poole \& F. Gill). Philadelphia: The Birds of North America.

Hoenig, J. M. \& Heisey, D. M. 2001. The abuse of power: the pervasive fallacy of power calculations for data analysis. American Statistician, 55, 19-24.

Holmes, A. L., Green, G. A., Morgan, R. L. \& Livezey, K. B. 2003. Burrowing owl nest success and burrow longevity in north central Oregon. Western North American Naturalist, 63 , 244-250.

Johnson, D. H. 2005. What hypothesis tests are not: a response to Colegrave and Ruxton. Behavioral Ecology, 16, 204-205.

Kerfoot, W. C. \& Sih, A. 1987. Predation: Direct and Indirect Impacts on Aquatic Communities. Hanover, New Hampshire: University Press of New England.

Kilham, L. 1968. Reproductive behavior of white-breasted nuthatches. Auk, 85, 477-492.

Knopf, F. L. \& Balph, D. F. 1969. Badgers plug burrows to confine prey. Journal of Mammalogy, 50, 635-636.

Levey, D. J., Duncan, R. S. \& Levins, C. S. 2004. Use of dung as a tool by burrowing owls. Nature, 431, 39. 
MacDonald, J. N. 1984. The recorded North American selection regime and late Quaternary megafaunal extinctions. In: Quaternary Extinctions: a Prehistoric History (Ed. by P. S. Martin \& R. G. Kein), pp. 404-439. Tucson: The University of Arizona Press.

Marti, C. D. 1974. Feeding ecology of four sympatric owls. Condor, 76, 45-61.

Martin, D. J. 1973. Selected aspects of burrowing owl ecology and behavior. Condor, 75, 446-456.

Martin, T. E. 2002. A new view for avian life history evolution tested on an incubation paradox. Proceedings of the Royal Society of London, 269, 309-316.

Møller, A. P., Baird, C., Blount, J. D., Houston, D. C., Ninni, P., Saino, N. \& Surai, P. F. 2000. Carotenoid-dependent signals: indicators of foraging efficiency, immunocompetence or detoxification ability? Poultry and Avian Biology Review, 11, 137-159.

Moran, J. A. 1996. Pitcher dimorphism, prey composition and the mechanisms of prey attraction in the pitcher plant in Borneo. Journal of Ecology, 84, 515-525.

Negro, J. J., Grande, J. M., Tella, J. L., Garrido, J., Hornero, D., Donázar, J. A., Sanchez-Zapata, J. A., Benítez, J. R. \& Barcell, M. 2002. Coprophagy: an unusual source of essential carotenoids. Nature, 416, 807-808.

Remes, V. \& Martin, T. E. 2002. Environmental influences on the evolution of growth and developmental rates in passerines. Evolution, 56, 2505-2518.

Rodriguez, I., Crespo, G., Fraga, S., Rodriguez, C. \& Prieto, D. 2003. Activity of the mesofauna and the macrofauna in dung patches during their decomposition process. Cuban Journal of Agricultural Science, 37, 315-322.
Rogers, L. E., Hinds, W. T. \& Buschbom, R. L. 1976. A general weight vs. length relationship for insects. Annals of the Entomological Society of America, 69, 387-389.

Rogers, L. E., Buschbom, R. L. \& Watson, C. R. 1977. Length and weight relationships for shrub-steppe invertebrates. Annals of the Entomological Society of America, 70, 51-53.

Ruggiero, R. G. \& Eves, H. E. 1998. Bird-mammal associations in forest openings of northern Congo. African Journal of Ecology, 36, 183-193.

Schuetz, J. G. 2004. Common waxbills use carnivore scat to reduce the risk of nest depredation. Behavioral Ecology, 16, 133-137. doi:10.1093/beheco/Arch139.

Scott, T. G. 1940. The western burrowing owl in Clay Co, lowa in 1938. American Midland Naturalist, 24, 585-593.

Selas, V. 1988. The response of common buzzard Buteo buteo to nest disturbance. Fauna-Oslo, 41, 16-19.

Smith, M. D. 2004. Function of manure-scattering behavior of burrowing owls. M.S. thesis, The University of Arizona.

Taylor, R. J. 1984. Predation. New York: Chapman \& Hall.

Tella, J. L., Figuerola, J., Negro, J. J., Blanco, G., Rodriguez-Estrella, R., Forero, M. G., Blazquez, M. C., Green, A. J. \& Hiraldo, F. 2004. Ecological, morphological and phylogenetic correlates of interspecific variation in plasma carotenoid concentration in birds. Journal of Evolutionary Biology, 17, 156-169.

Thomsen, L. 1971. Behavior and ecology of burrowing owls on the Oakland municipal airport. Condor, 73, 177-192.

Wellicome, T. I. 2000. Effects of food on reproduction in burrowing owls during three stages of the breeding season. Ph.D. thesis, University of Alberta.

Ydenberg, R. C. \& Dill, L. M. 1986. The economics of fleeing from predators. Advances in the Study of Behavior, 16, 229-249. 